\title{
Lessons learned from non-medical industries: the tragedy of the USS Greeneville*
}

\author{
K H Roberts, C T Tadmor
}

Qual Saf Health Care 2002; 11:355-357

In February 200l the nuclear powered submarine USS Greeneville collided with the Japanese fishing trawler Ehime Maru, killing nine passengers. A series of small failures and hurried actions escalated into tragedy. This incident provides lessons learned that can be used by healthcare organizations to improve patient safety. Expertise, training, equipment, and procedures appeared to be adequate protection, yet the presence of multiple defences obscured their faulty functioning, just as they often do in medical settings. A number of other problems occurred aboard Greeneville which we also see in health care. The problem was the total breakdown of communication. The Greeneville team also failed to move from a rigid hierarchical structure to a more flexible adaptive structure. Communication often breaks down in healthcare settings, which are organized to maximize status and hierarchical differences, thus often impeding information flow needed to make decisions. Redundancy failed aboard Greeneville as it often does in medicine. Finally, the Captain of the Greeneville established an artificially hurried situation. Time constrained situations happen all the time in health care. We recommend strategies to mitigate the development of these kinds of processes.

See end of article for authors' affiliations

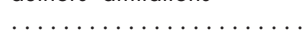

Dr K H Roberts, University of California, Berkeley, CA, USA;

karlene@haas.berkeley.edu

\section{THE SETTING}

On 9 February 2001, during a distinguished visitor's tour, a US nuclear powered submarine, the USS Greeneville, collided with and sank a Japanese fishing trawler, the Ehime Maru, killing nine of her 35 passengers. ${ }^{1}$ How a ship like Greeneville could be involved in such a tragedy is perplexing, particularly because Greeneville and the rest of the US submarine force are renown for reliability. Aboard submarines everyone has the explicit order to "back up" senior leadership, calling into question their actions when necessary. Unlike the hierarchical structure evident when submarines are in port and little is happening, at sea the organization shifts to a more fluid structure that allows decisions to be made by front line personnel knowledgeable about rapidly changing conditions.

The plan was simple. The ship was to get underway with 16 visitors, conduct a dive, then a deep dive, and serve lunch. After lunch she was scheduled to conduct two standard manoeuvring tactics to show off her capabilities: a set of high speed "angles and dangles" showing the ship's ability to handle itself when rapidly changing depths, and an "emergency blow" in which the submarine rapidly shoots out of the water to a surfaced position. Upon completion the ship was to return to Pearl Harbor.

\section{Problems appear}

Problems began during a routine periscope search before getting underway. The Officer of the Deck (OOD) noticed a hazy, off white sky on the horizon (an unusual condition off the Hawaiian coast) that made it difficult to pick up light hulled ships (the Ehime Maru was predominantly white). He failed to pass this information on to his relief. The OOD also discovered that a sonar video monitor was out of commission. Although it creates a handicap, the ship can operate safely without it, but it should have alerted the crew to add additional actions to reduce risk. However, no actions were taken to ensure that appropriate compensatory measures were instituted and passed down to subsequent watch standers.

After the deep dive and a tour of the submarine, the visitors ate lunch which ran late. The ship's time frame was flexible so, if it ran late, the Captain could inform Port Operations and the necessary schedule adjustments would be made without reflecting badly on the ship's performance. No request was made to delay the return.

\section{Problems compound}

In an effort to save time during the performance of "angles and dangles", the Captain took the controlst, turning the OOD into a relay and thereby preventing essential back up. Upon completion of "angles and dangles" the Captain, reluctant to cancel any of the planned activities and reminded by the Executive Officer of the time and distance to port, began hurried preparations for the emergency blow surfacing procedure.

*All of the data for this case were drawn from the following sources: Collision summary, final report. Court of Inquiry into the circumstances surrounding the collision between USS Greeneville (SSN 772) and Japanese M/V Ehime Maru that occurred off the coast of Oahu, Hawaii on 9 February 2001. Court of Inquiry convened at trial service office by order of the Commander in Chief, United States Pacific Fleet to inquire into a collision between USS Greeneville (SSN 72) and the Japanese M/V Ehime Maru that occurred off the coast of Oahu, Hawaii on 9 February 2001. NTSB advisory (2 March 2001) National Transportation Safety Board, Washington D.C. 20594. USS Greeneville/Ehime Maru collision update (March 2001).

†The captain should only take the CONN if the ship is in extremis. 
Since such high speed manoeuvres disrupt sonar data, new sonar data must be collected and analysed before reaching periscope depth.

Each sonar contact must be viewed from two different perspectives to triangulate location and direction of motion. Data collection from each perspective requires 3-5 minutes to complete. Nonetheless, the Captain ordered the OOD to get to periscope depth in 5 minutes. The Captain testified that he gave the order as a training goal to a methodical and inexperienced OOD, knowing that this was an impossible task. By doing this he broke all the rules of risk management. Because of the incomprehensible appearance of the sonar data and the hurried surfacing, the lengths of the searches were insufficient to allow accurate processing and dissemination of the sonar data.

The ship then conducted a procedure in which it repositions itself to better listen for contacts it might have missed because of the increased stern noise caused by the propellers. This change in course, just before coming up to periscope depth, revealed a new contact. Once reported, the contact management team should spend about 3 minutes on course gaining an accurate first search of the new contact, and then proceed to a different course for an additional 3 minutes to get a second perspective. Because of the broken video monitor, the Captain and the OOD did not recognize the new contact and failed to conduct a second search to pinpoint it.

Neither the sonar supervisor nor the fire control technician of the watch, both of whom were aware that this was a new contact, requested a second search. In the crucial minutes before ascending to periscope depth, the fire control technician considered the new contact to be of primary interest because of the single search solution of 8000 yards, a distance considered relatively close. Preoccupied with the new contact and pressed for time, the fire control technician failed to pay attention to the new computer generated 4000 yard closing solution he had entered for Ehime Maru which, according to Navy regulations, must be reported immediately to the OOD. According to this solution, Ehime Maru had moved from 14000 yards to 4000 yards away in an impossibly short time at the speeds of these vessels. At this point it was the fire control technician's duty to tell the Captain forcefully that they were going to collide with the Ehime Maru if they completed the "emergency blow". He said nothing.

The fire control technician also failed to properly update the contact evaluation plot, a large paper display with plotted bearings of all contacts. This usually redundant display has special importance when the sonar video monitor is not working. The fire control technician admitted he "got lazy". In order to maintain the plot, he had to manoeuvre himself through the visitors who were in the control room and were blocking his way. Instead, he focused on obtaining solutions for targets and he didn't communicate with the sonar operator to develop consensus on a contact picture to present to the Captain.

\section{Final defences fail}

The next to last defence is a briefing typically conducted before going to periscope depth in which the OOD, after consulting with the sonar supervisor and the fire control technician, informs the Captain about all contacts. It was not held. Not only would this briefing have allowed the sonar operator and the fire control technician to inform the OOD of the new contact, but the extra time would have allowed the sonar operator to regain a clear picture of the contacts. The Captain's own situational awareness was based on two brief walk throughs of the sonar data and a single review of the fire control displays. Confident that he knew the contacts and feeling pressed for time, the Captain failed to use the team to confirm his understanding of the situation. These actions effectively disabled essential back up and squandered the opportunity to

\section{Box 1 Problems aboard Greeneville}

- Video monitor that tracks the courses of other ships failed

- Response to monitor breakdown was "business as usual" instead of hypervigilance

- Lunch ran late

- The Captain took the controls and failed to use the crew as "back up"

- Communication broke down among crew members

- Initial periscope depth observation gave cause for concern that wasn't noted

- The fire control technician did not update the plot of contacts

- The sonar data collection and analysis was abbreviated

- Fire control and sonar failed to notice discrepancies in position of Ehime Maru

- The final briefing was not held

- The final periscope search was abbreviated

clarify the confusion and ascertain reliable data. The Captain proceeded to direct the OOD to proceed to periscope depth.

Once the ship arrives at periscope depth a search is conducted. Additional sensors, such as the periscope eyepiece and an antenna, become available. Initially, two or three rapid revolutions looking through the periscope eyepiece are conducted to determine any possible contacts. If there are no contact sightings, the OOD switches to a more deliberate search. This takes about 3 minutes. That day, after the OOD conducted the initial rapid search, the Captain proceeded to do the more deliberate search. Behind schedule, the Captain took the periscope and conducted an abbreviated non-standardized search. The turbulent waves and background haze made visibility more difficult. Confident that all contacts were distant, the Captain ordered the emergency blow ascent to proceed.

A summary of the problems aboard the Greeneville is shown in box 1 .

\section{LESSONS FOR HEALTH CARE}

Healthcare organizations, like the Greeneville, pride themselves on being high performers. When we see calamities in the healthcare industry, the processes that lead to them are often similar to those in the Greeneville case.$^{2-4}$ Expertise, training, equipment, and procedures appeared to be adequate protection, yet the presence of multiple defences obscured their faulty functioning. An accumulation of small errors without compensatory actions was sufficient to bring about disaster. ${ }^{56}$

The first apparent problem was the total breakdown of communication. The "back up", which is the hallmark of submarine operations, failed. Communication often fails in health care because there are so many hand offs that are opportunities for communication failures-for example, when patients are transferred from operating rooms to intensive care unit teams. ${ }^{7}$ When physical equipment malfunctions or is missing, the care team needs to compensate by paying particular attention to the quality of its communications.

The second major issue was the failure of the Greeneville team to move from a rigid hierarchical structure to a more flexible adaptive structure. When a team is faced with a rapidly changing and fluid situation, it needs to reconfigure itself to address the challenge better. ${ }^{8}$ Teams must be capable of decentralizing decisions and integrating individual assignments to increase effectiveness. Instead, the Captain made all the crucial decisions without consulting his subordinates and

łInfamous cases include the Willie King wrong leg surgery case, the Betsy Lehman death from chemotherapy overdose, and the unexplained death of 18 year old Libby Zion. 


\section{Box 2 Quotations from the Court of Inquiry}

"The more directive the Commanding Officer becomes in giving detailed orders, the less he's able to supervise the operation of the team overall and becomes de facto the quarterback and is operating the team himself. That's a danger here ...you're now dependent upon one man making all the decisions and that's a risky situation in my opinion." Captain Thomas Kyle, Court of Inquiry, day 5, p 67

"That's what's so challenging about this case. You have a ship that does operate well, that has a history of professionalism and excellence. You have clearly qualified and excellent people who intend to do well, mean to do well in their positions of responsibility on the ship, and yet you have this tragedy for perhaps because of this accretion of subtle measures not completely taken." Rear Admiral Charles H Griffiths, Court of Inquiry, day 4, p 24

took over tasks normally carried out by others (box 2). Health care is organized to maximize status and hierarchical differences, thus impeding information flow needed to make decisions. Top leadership must be able to seek the advice of all team members, encouraging them to speak up in a respectful way, and not allow the authority gradient to impede the flow of vital information. ${ }^{9-11}$

By centralizing decisions, the Captain also undermined the effectiveness of teamwork. ${ }^{12}$ We see this in health care when surgical teams including surgeons and anesthesiologists don't work as a cohesive group, or the ward nurses and physicians try to avoid one another. Worse still, we often see people either psychologically or physically leaving the scene, as did the fire control technician when he "got lazy".

Healthcare settings need effective redundancy, such as in surgical teams where senior members check the work of junior members of the team or in emergency room teams where members can switch some roles to cover for each other when necessary. Redundancy was built into the Greeneville's daily work yet failed to function. The video monitor failed and various individuals failed to back each other up and transmit key information. ${ }^{13}$ Briefings and tests were skipped or abbreviated, yet no one heeded the eroding state of safety defences.

Finally, we observe that, for one reason or another, the Captain of the Greeneville established an artificially hurried situation. Time constrained situations happen all the time in health care. But the Greeneville tragedy should serve as an example of the value of slowing things down to enhance reliability and address all safety concerns. The Captain, feeling the time pressure, took well intentioned shortcuts that reduced the available information from his own periscope search and from his crew. Members of the crew avoided moving through the mass of visitors in a close space. In health care, physicians are hurried because HMOs penalize them for longer patient visits. Teams preparing for surgeries may miss vital signs when rushing to handle the backlog of waiting patients. Under time pressure (real or imagined), there is a tendency to skip critical tasks and focus on what is immediately at hand, leading to fixation errors and difficulty in stepping back to regain the big picture.

The Greeneville case provides evidence that organizations, even those which pride themselves on perfection, can create catastrophic events from a series of seemingly benign events,

\section{Box 3 A checklist for healthcare organizations}

- Are observations of situational cues and indicators routinely done and reported to others?

- Does the system have in place equipment failure back ups? Are they used?

- Can everyone openly discuss errors, near misses, and adverse events?

- Is teamwork taught and valued in the running of the organization?

- Does the leadership recognize possible time and resource constraints and reduced redundancy, and take extra steps to compensate for increased risks?

\section{Key messages}

To maintain safety healthcare organizations must:

- Routinely make observations of situational cues and indicators of poor safety and report them to accountable sources.

- Ensure equipment failure back ups exist and are used.

- Ensure that everyone openly discusses errors, near misses, and adverse events.

- Value and teach teamwork in the running of the organization.

- Develop a leadership team that can recognize possible time and resource constraints and reduced redundancy, and will take extra steps to compensate for increased risks.

no one of which would have sunk the Ehime Maru. Minor malfunctions and near misses created additional stress and demands on participants, thus contributing to the failure to follow up on apparently inconsequential events. This stripped away opportunities to prevent or mitigate the tragedy (see box 2). Healthcare organizations must continue to identify, enhance, and perfect processes that protect them against serious adverse outcomes. A checklist for healthcare organisations is shown in box 3 .

\section{Authors' affiliations}

K H Roberts, C T Tadmor, University of California, Berkeley, CA, USA

\section{REFERENCES}

1 Tadmor CT, Roberts KH. Structural failure and the development of an organizational breakdown: the tragedy of the USS Greeneville. Working paper, University of California, Berkeley, 2002.

2 Clary M. String of errors put Florida hospital on the critical list. Los Angeles Times, 14 April 1991, part A: 1.

3 Goodman E. The diagnosis: losing patients, losing faith. The Plain Dealer, 2 April, 1995, perspective: 3C

4 Agus C. Zion nurse didn't want to "hang" doc. Newsday, 2 December 1994, news: A33.

5 Turner BM. Man made disasters. London: Wykeham Press, 1978

6 Rudolph J, Repenning NP. Disaster dynamics: understanding the role of quantity in organizational collapse. Admin Sci Q 2002;47: 1-30.

7 Roberts KH, Yu K. The space between. Working paper, University of California, Berkeley, 2002

8 Bigley GA, Roberts KH. Structuring temporary systems for high reliability. Acad Manage J 2001;44:1281-300.

9 Vaughan D. Autonomy, interdependence, and social control: the space shuttle Challenger. Admin Sci Q 1990;35:225-57.

10 Vaughan D. The Challenger launch decision: risky technology, culture, and deviance at NASA. Chicago: University of Chicago Press, 1996.

11 Edmondson A. Psychological safety and learning behavior in work teams. Admin Sci Q 1999;44:350-83.

12 Weick KE. The collapse of sensemaking in organizations: the Mann Gulch disaster. Admin Sci Q 1993;38:628-52.

13 Roberts KH. Some characteristics of one type of high reliability organization. Organ Sci 1990;1:160-76. 